\title{
SOLID MODELING USING BOUNDARY INTEGRAL EQUATIONS
}

\author{
Yoshihiro OCHIAI
}

Kinki University, 3-4-1 Kowakae, Higashi-Osaka City, 577-8502, Japan

\begin{abstract}
This paper describes a method of solid modeling using boundary integral equations and three-dimensional polyharmonic functions. This method requires arbitrary points and lines on a free-form surface of a solid model. The free-form surfaces of the solid model are searched, after solving the discretized integral equation. In this paper, the integrated polyharmonic functions are derived. These functions effectively smooth the obtained surface even if functions of low order are used. The complicated and smooth free-form surface of the solid model can be expressed by only one surface patch. In order to investigate the efficiency of this method, several examples are presented.
\end{abstract}

Key Words: Modeling, Drawing, Surface Generation, CAD, Boundary Element Method, Design

\section{INTRODUCTION}

In defining a free-form surface in interactive $\mathrm{CAD}$, surfaces are generated using a Bézier spline and a B-spline ${ }^{1,2}$. In the method using the B-spline, points must be assigned in a gridiron layout. Partial differential equations(PDE) are used to generate many kinds of free-form surfaces ${ }^{3}$. However, PDE cannot use scattered data. Optimization techniques are used to generate a smooth free-form surface, which is a B-spline surface ${ }^{4}$. A method using soft objects has been proposed ${ }^{5,6}$,but it is difficult to define an exact position of points on a surface. On the other hand, the radius spline is proposed $^{7,8}$. The author has proposed a method using boundary integral equations and polyharmonic functions in order to generate a 2.5-dimensional free-form surface ${ }^{9,10,11}$. In the above-mentioned two methods, points can be assigned arbitrarily instead of using a gridiron layout, making it easy to generate a free-form surface. In the method using the integral equations, it is quite simple to generate a 2.5-dimensional free-form surface.

This paper describes a method of solid modeling using boundary integral equations and the three-dimensional polyharmonic functions. In 
this paper, a fictitious big box, in which a solid is defined, is considered. In order to obtain a smooth surface using lower-order polyharmonic functions, a new function, which expresses a state of a uniformly distributed polyharmonic function in a spherical region, is introduced. A new integral equations are proposed using these new functions.

\section{THEORY}

\subsection{Fundamental equation}

In this theory, the Poisson equation, which is used for heat conduction analysis with heat generation, is applied to define a solid geometry. In the one-dimensional case, linear interpolation, as shown in Fig.1, can be described by

$$
\nabla_{(1)}^{2} \mathrm{~T}_{1}=-\mathrm{T}_{2}^{\mathrm{P}}
$$

where $\nabla_{(1)}{ }^{2}$ is $\mathrm{d}^{2} / \mathrm{dx}^{2}$. The term $\mathrm{T}^{\mathrm{p}}{ }_{2}$ corresponds to an unknown point heat source. Smoother interpolation is obtained by

$$
\begin{gathered}
\nabla_{(1)}{ }^{2} \mathrm{~T}_{1}=-\mathrm{T}^{\mathrm{S}}{ }_{2} \\
\nabla_{(1)}{ }^{2} \mathrm{~T}_{2}=-\mathrm{T}^{\mathrm{P}}{ }_{3} .
\end{gathered}
$$

From Eqs.(2) and (3), the following equation can be obtained.

$$
\nabla_{(1)}{ }^{4} \mathrm{~T}_{1}=\mathrm{T}_{3}{ }^{\mathrm{P}}
$$

This equation is the same type of equation as that for the deformation $\left(T_{1}\right)$ of a thin beam with an unknown point load $\left(\mathrm{T}^{\mathrm{p}}{ }_{3}\right)$. The unknown point load

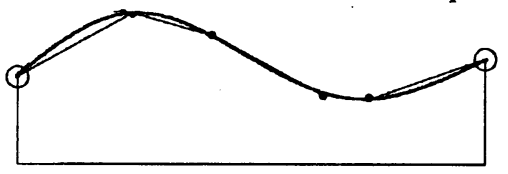

(a) Linear interpolation Figure.1 One-dimensional interpolation

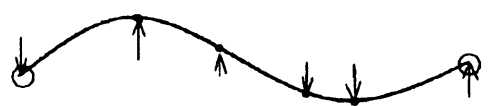

(b) Beam for interpolation

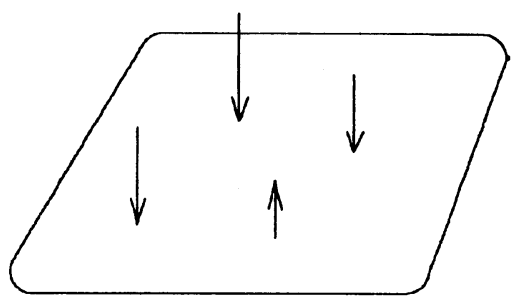

Figure.2 Fictitious thin plate for interpolation 
$\left(\mathrm{T}^{\mathrm{P}}{ }_{3}\right)$ can be obtained inversely using a value of $\mathrm{T}_{1}$ at several points, as shown in Fig.2. The term $\mathrm{T}_{2}^{\mathrm{S}}$ corresponds to the moment of the beam, and the term $\mathrm{T}^{\mathrm{s}}{ }_{2}$ at both ends of the beam is assumed to be 0 . The obtained curve corresponds to the natural spline.

In the two-dimensional case, interpolation can be describe by (Ochiai and Yasutomi ${ }^{13}, 2000$ )

$$
\begin{gathered}
\nabla_{(2)}{ }^{2} \mathrm{~T}_{1}=-\mathrm{T}^{\mathrm{S}}{ }_{2} \\
\nabla_{(2)}{ }^{2} \mathrm{~T}_{2}^{\mathrm{S}}=-\mathrm{T}^{\mathrm{P}}{ }_{3},
\end{gathered}
$$

where $\nabla_{(2)}{ }^{2}=\partial^{2} / \partial x^{2}+\partial^{2} / \partial y^{2}$. From Eqs.(5) and (6), the following equation can be obtained.

$$
\nabla_{(2)}{ }^{4} \mathrm{~T}_{1}=\mathrm{T}^{\mathrm{P}}
$$

This equation is the same type of equation as that for the deformation $\left(\mathrm{T}_{1}\right)$ of a thin plate with an unknown point load $\left(\mathrm{T}^{\mathrm{P}}{ }_{3}\right)$, as shown in Fig.2. The unknown point load $\left(\mathrm{T}_{3}^{\mathrm{P}}\right)$ can be obtained inversely using a value of $\mathrm{T}_{1}$ at several points. The smoother free-form surface can be obtained using a uniformly distributed load $\left(\mathrm{T}^{\mathrm{P}}{ }_{3 \mathrm{~A}}\right)$ on area $\mathrm{A}$ instead of a point load $\left(\mathrm{T}^{\mathrm{P}}{ }_{3}\right)$. (Ochiai and Yasutomi, 2000) A 2.5-dimensional free-form surface can be obtained using the above-mentioned method. Figure 3(a) shows a line of given boundary geometry and arbitrary internal points. Figure $3(b)$ shows an obtained shape.

In the three-dimensional case, the Poisson equation, which is used for heat conduction analysis with heat generation, is applied to define a solid geometry. Solid geometry is assumed as the part of which values are less than zero. It is assumed that the value $T_{1}$ at an arbitrary point $P$ satisfies the Poisson equation

$$
\nabla^{2} \mathrm{~T}_{1}=-\mathrm{T}_{2},
$$

The term $T_{2}$ is a function of $(x, y, z)$ including infinite values. It corresponds to the sum of approximated

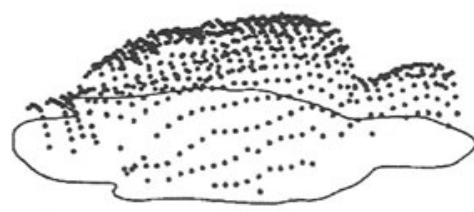

(a) Given data

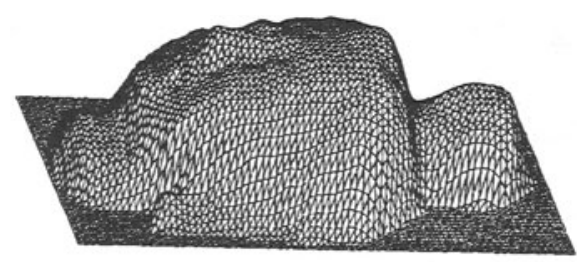

(b) Obtained shape

Figure.3 2.5-dimensional shape 


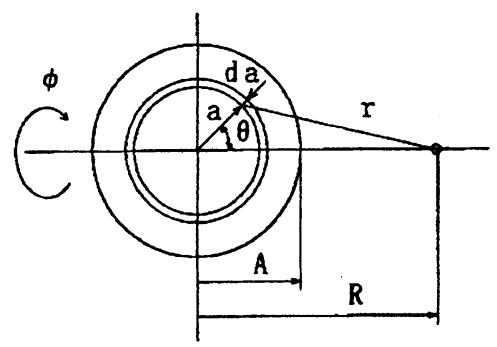

Figure.4 Notations for new function

curvatures $\partial^{2} \mathrm{~T}_{1} / \partial \mathrm{x}^{2}, \partial^{2} \mathrm{~T}_{1} / \partial \mathrm{y}^{2}$ and $\partial^{2} \mathrm{~T}_{1} / \partial \mathrm{z}^{2}$. The surface of the solid is an iso-surface with value 0 . The three-dimensional $i$-th polyharmonic function $T^{*}(P, Q)$ and its normal derivative $\partial T^{*} / \partial$ n can be given by ${ }^{9}$

$$
\begin{aligned}
& \mathrm{T}^{*}{ }_{i}(\mathrm{P}, \mathrm{Q})=\frac{\mathrm{r}^{2 \mathrm{i}-3}}{4 \pi(2 \mathrm{i}-2) !} \\
& \frac{\partial \mathrm{T}^{*}}{\partial \mathrm{n}}=\frac{(2 \mathrm{i}-3) \mathrm{r}^{2 \mathrm{i}-3}}{4 \pi(2 \mathrm{i}-2) !} \frac{\partial \mathrm{r}}{\partial \mathrm{n}}
\end{aligned}
$$

Denoting by $r$ the distance between two points $(P, Q)$, where $P$ and $Q$ are the source point and the observing point, respectively.

In order to obtain a smooth surface using lower order polyharmonic functions, a new function $T^{*}{ }_{i A}$, which expresses the state of a uniformly distributed polyharmonic function in a spherical region with radius $A$, as shown in Fig.4, is introduced.

$$
\mathrm{T}^{*}{ }_{\mathrm{iA}}=\int_{0}^{\mathrm{A}} \int_{0}^{2 \pi} \int_{0}^{2 \pi} \mathrm{T}^{*} \mathrm{iad} \theta \mathrm{d} \phi \mathrm{da}
$$

The newly defined function $T^{*}{ }_{i A}$ and its normal derivative are shown explicitly. These functions are given by using $\mathrm{r}$ similarly in Eqs.(9) and (10), though the functions obtained from Eq.(11) are the functions of R.

$$
\begin{array}{rlrl}
T^{*}{ }_{1 A} & =\frac{A^{3}}{3 r} & r>A \\
T^{*}{ }_{1 A} & =\frac{3 A^{2}-r^{2}}{6} & r \leqq A \\
T^{*}{ }_{2 A} & =\frac{A^{3}}{6 r}\left[r^{2}+\frac{A^{2}}{5}\right] & r>A \\
T^{*}{ }_{2 A} & =-\frac{r^{4}-15 A^{4}-10 r^{2} A^{2}}{120} & r & r A
\end{array}
$$

The term $\mathrm{T}_{2}$ in Eq.(8) can be divided into several terms as follows ${ }^{9-11}$ : 


$$
\mathrm{T}_{2}=\mathrm{T}^{\mathrm{V}}{ }_{2}+\mathrm{T}^{\mathrm{S}}{ }_{2}+\mathrm{T}^{\mathrm{L}}+\mathrm{T}_{2}^{\mathrm{P}}+\mathrm{T}^{\mathrm{D}}+\mathrm{T}_{2 \mathrm{~A}}^{\mathrm{S}}+\mathrm{T}^{\mathrm{D}}{ }_{2 \mathrm{~A}}+\mathrm{T}^{\mathrm{L}}{ }_{2 \mathrm{~A}}+\mathrm{T}^{\mathrm{P}}{ }_{2 \mathrm{~A}}
$$

where $T^{P}$ is a Dirac-type function, which has a value only at a point and similarly $\mathrm{T}^{\mathrm{L}}{ }_{2}$ has the value only on a line and $\mathrm{T}^{\mathrm{S}}{ }_{2}$ on a surface. Moreover, point $T_{2 A}^{P}$ and line $T_{2 A}^{L}$ are related to the new function $T_{2 A}$. On the other hand $\mathrm{T}_{2}^{\mathrm{D}}$ and $\mathrm{T}^{\mathrm{D}}{ }_{1 \mathrm{~A}}$ are concerned with $\partial \mathrm{T}_{\mathrm{i}} / \partial \mathrm{n}$ and $\partial \mathrm{T}_{\mathrm{i}} / \partial \mathrm{n}$, which correspond to the double layer along a form of a surface. Equation (8) can be written as follows:

$$
\nabla^{2} \mathrm{~T}_{1}^{\mathrm{V}}=-\left(\mathrm{T}^{\mathrm{V}}{ }_{2}+\mathrm{T}^{\mathrm{S}}+\mathrm{T}^{\mathrm{L}}{ }_{2}+\mathrm{T}^{\mathrm{P}}{ }_{2}+\mathrm{T}^{\mathrm{D}}{ }_{2}+\mathrm{T}^{\mathrm{S}}{ }_{2 \mathrm{~A}}+\mathrm{T}^{\mathrm{D}}{ }_{2 \mathrm{~A}}+\mathrm{T}^{\mathrm{L}}{ }_{2 \mathrm{~A}}+\mathrm{T}^{\mathrm{P}}{ }_{2 \mathrm{~A}}\right)
$$

Generally, the next equation

$$
\nabla^{2} T^{v}{ }_{i}=-\left(T^{v}{ }_{i+1}+T^{S}{ }_{i+1}+T^{L}{ }_{i+1}+T^{P}{ }_{i+1}+T^{D}{ }_{i+1}+T^{S}{ }_{i+1 A}+T^{D}{ }_{i+1 A}+T^{L}{ }_{i+1 A}+T^{P}{ }_{i+1 A}\right)
$$

is assumed. Moreover, in the case of $i=I$, we assume $T^{v}{ }_{I+1}=0$ and we obtain

$$
\nabla^{2} \mathrm{~T}^{\mathrm{V}}=-\left(\mathrm{T}^{\mathrm{V}}{ }_{\mathrm{l}+1}+\mathrm{T}_{\mathrm{l}+1}^{\mathrm{S}}+\mathrm{T}_{\mathrm{l}+1}^{\mathrm{L}}+\mathrm{T}_{\mathrm{l}+1}^{\mathrm{P}}+\mathrm{T}^{\mathrm{D}}{ }_{\mathrm{l}+1}+\mathrm{T}_{\mathrm{I}+1 \mathrm{~A}}^{\mathrm{S}}+\mathrm{T}_{\mathrm{l}+1 \mathrm{~A}}^{\mathrm{D}}+\mathrm{T}_{\mathrm{l}+1 \mathrm{~A}}^{\mathrm{L}}+\mathrm{T}_{\mathrm{I}+1 \mathrm{~A}}^{\mathrm{P}}\right)
$$

Considering the fictitious box as a boundary $\Gamma$, the value $T_{1}$ at an arbitrary point is given by Eqs.(8) and (16) (19) and Green's second identity as follows ${ }^{9-11}$ :

$$
\begin{aligned}
& \mathrm{cT}^{\mathrm{v}}{ }_{1}(\mathrm{P})=-\sum_{i=1}^{\mathrm{l}}(-1)^{\mathrm{i}} \int_{\Gamma}\left\{\mathrm{T}^{*}{ }_{\mathrm{i}}(\mathrm{P}, \mathrm{Q}) \frac{\partial \mathrm{T}^{\mathrm{v}}{ }_{\mathrm{i}}(\mathrm{Q})}{\partial \mathrm{n}}-\frac{\partial \mathrm{T}^{*}{ }_{i}(\mathrm{P}, \mathrm{Q})}{\partial \mathrm{n}} \mathrm{T}^{\mathrm{v}}{ }_{\mathrm{i}}(\mathrm{Q})\right\} \mathrm{d} \Gamma(\mathrm{Q}) \\
& -\sum_{i=1}^{1} \int_{r_{s}}(-1)^{i} T^{*}{ }_{i} T^{s}{ }_{i+1} d \Gamma_{s}-\sum_{i=1}^{l}(-1)^{i} T^{*}{ }_{i}(P, q) T^{P}{ }_{i+1}(q) \\
& -\sum_{i=1}^{\mathrm{I}} \int_{\Gamma_{\mathrm{L}}}(-1)^{\mathrm{i}} \mathrm{T}^{*}{ }_{\mathrm{i}} \mathrm{T}^{\mathrm{L}}{ }_{\mathrm{i}+1} \mathrm{~d} \Gamma_{\mathrm{L}}-\sum_{\mathrm{i}=1}^{\mathrm{I}} \int_{\Gamma_{\mathrm{D}}}(-1)^{\mathrm{i}} \frac{\partial \mathrm{T}^{*}{ }_{\mathrm{i}}}{\partial \mathrm{n}^{\prime}} \mathrm{T}^{\mathrm{D}}{ }_{\mathrm{i}+1} \mathrm{~d} \Gamma_{\mathrm{D}} \\
& -\sum_{i=1}^{\mathrm{I}} \int_{\Gamma_{\mathrm{S}}}(-1)^{\mathrm{i}} \mathrm{T}^{*}{ }_{\mathrm{iA}} \mathrm{T}^{\mathrm{s}}{ }_{\mathrm{i}+1 \mathrm{~A}} \mathrm{~d} \Gamma_{\mathrm{S}}-\sum_{\mathrm{i}=1}^{\mathrm{l}}(-1)^{\mathrm{i}} \mathrm{T}^{*}{ }_{\mathrm{iA}}(\mathrm{P}, \mathrm{q}) \mathrm{T}^{\mathrm{P}}{ }_{\mathrm{i}+1 \mathrm{~A}}(\mathrm{q}) \\
& -\sum_{i=1}^{1} \int_{\Gamma_{L}}(-1)^{i} T^{*}{ }_{i A} T^{L}{ }_{i+1 A} d \Gamma_{L}-\sum_{i=1}^{I} \int_{\Gamma_{D}}(-1)^{i} \frac{\partial T_{i A}}{\partial n^{\prime}} T^{D_{i+1}} d \Gamma_{D}
\end{aligned}
$$

where $\Gamma_{S}, \Gamma_{L}$ and $\Gamma_{D}$ show the forms of $T^{s}, T^{L}{ }_{i}$ and $T^{D}{ }_{i}$. On the smooth boundary $\Gamma c=0.5$, for the inside of the boundary $c=1.0$ and for the outside of the boundary $c=0$.

2.2 Unit normal vector Unit normal vector on a surface is important in CAD. Differentiating Eq.(20) with $x_{k}$, the next equation is obtained. 


$$
\begin{aligned}
& \frac{\partial \mathrm{T}^{\mathrm{v}}{ }_{1}(\mathrm{P})}{\partial \mathrm{x}_{\mathrm{k}}}=-\sum_{\mathrm{i}=1}^{\mathrm{l}}(-1)^{i} \int_{\Gamma}\left\{\frac{\partial \mathrm{T}_{\mathrm{i}}^{*}}{\partial \mathrm{x}_{\mathrm{k}}} \frac{\partial \mathrm{T}_{\mathrm{i}+1}^{\mathrm{v}}}{\partial \mathrm{n}}-\frac{\partial^{2} \mathrm{~T}_{\mathrm{i}}^{*}}{\partial \mathrm{x}_{\mathrm{k}} \partial \mathrm{n}} \mathrm{T}^{\mathrm{v}}{ }_{i}(\mathrm{Q})\right\} \mathrm{d} \Gamma(\mathrm{Q}) \\
& -\sum_{i=1}^{1} \int_{\Gamma_{s}}(-1)^{i} \frac{\partial T^{*}{ }_{i}}{\partial x_{k}} T^{s}{ }_{i+1} d \Gamma_{S}-\sum_{i=1}^{l}(-1)^{i} \frac{\partial T^{*}{ }_{i}(P, q)}{\partial x_{k}} T^{P}{ }_{i+1}(q) \\
& -\sum_{i=1}^{1} \int_{\Gamma_{L}}(-1)^{i} \frac{\partial T^{*} i}{\partial x_{k}} T^{L}{ }_{i+1} d \Gamma_{L}-\sum_{i=1}^{1} \int_{\Gamma_{D}}(-1)^{i} \frac{\partial^{2} T_{i}^{*}}{\partial x_{k} \partial n^{\prime}} T^{D}{ }_{i+1} d \Gamma_{D} \\
& -\sum_{i=1}^{1} \int_{\Gamma_{s}}(-1)^{i} \frac{\partial T^{*}{ }_{i A}}{\partial x_{k}} T^{s}{ }_{i+1 A} d \Gamma_{s}-\sum_{i=1}^{l}(-1)^{i} \frac{\partial T^{*}{ }_{i A}(P, q)}{\partial x_{k}} T^{P_{i+1 A}}(q) \\
& -\sum_{i=1}^{1} \int_{\Gamma_{L}}(-1)^{i} \frac{\partial T^{*}{ }_{i A}}{\partial x_{k}} T^{L_{i+1 A}} d \Gamma_{L}-\sum_{i=1}^{1} \int_{\Gamma_{D}}(-1)^{i} \frac{\partial^{2} T^{*}{ }_{i A}}{\partial x_{k} \partial n^{\prime}} T^{D_{i+1 A}} d \Gamma_{D},
\end{aligned}
$$

where

$$
\begin{aligned}
& \frac{\partial T_{i}^{*}}{\partial x_{k}}=\frac{(2 i-3) r_{, k} r^{2 i-4}}{4 \pi(2 i-2) !} \\
& \frac{\partial^{2} T_{i}^{*}}{\partial x_{k} \partial n}=\frac{r_{, k} r^{2 i-5}}{4 \pi(2 i-2) !}\left[n_{k}+r_{,_{k}}(2 i-5) \frac{\partial r}{\partial n}\right]
\end{aligned}
$$

Functions $\partial \mathrm{T}_{\mathrm{i} A} / \partial \mathrm{x}_{\mathrm{k}}$ are given as follows:

$$
\begin{array}{rlrl}
\frac{\partial T^{*}{ }_{1 A}}{\partial x_{k}} & =-\frac{A^{3}}{3 r^{2}} \frac{\partial r}{\partial x_{k}} & & r>A \\
\frac{\partial T^{*}{ }_{1 A}}{\partial x_{k}} & =-\frac{r}{3} \frac{\partial r}{\partial x_{k}} & r & r \leqq A \\
\frac{\partial T^{*}{ }_{2 A}}{\partial x_{k}} & =-\frac{A^{3}\left(r^{2}-5 A^{2}\right)}{30 r^{2}} \frac{\partial r}{\partial x_{k}} & & r>A \\
\frac{\partial T^{*}{ }_{2 A}}{\partial x_{k}} & =-\frac{r^{3}-5 r A^{2}}{30} \frac{\partial r}{\partial x_{k}} & r & \text { }
\end{array}
$$

The $\mathrm{N}_{\mathrm{i}}$ component of a unit normal vector is given by

$$
\mathrm{N}_{\mathrm{i}}=\frac{\frac{\partial \mathrm{T}^{\mathrm{v}}{ }_{1}(\mathrm{P})}{\partial \mathrm{x}_{i}}}{\sqrt{\frac{\partial \mathrm{T}^{\mathrm{V}}{ }_{1}(\mathrm{P})}{\partial \mathrm{x}_{\mathrm{i}}} \times \frac{\partial \mathrm{T}^{\mathrm{v}}{ }_{1}(\mathrm{P})}{\partial \mathrm{x}_{\mathrm{i}}}}}
$$




\section{NUMERICAL PROCEDURE OF INTEGRAL EQUATION}

As it is difficult to treat the integral equation (20) analytically, they are discretized and treated numerically. Various examples using integral equations can be shown. In this paper, the term $\mathrm{T}_{3 \mathrm{~A}}^{\mathrm{P}}$ and $\mathrm{I}=2$ are used. We obtain the following equations from Eqs.(17) and (19).

$$
\begin{aligned}
\nabla^{2} \mathrm{~T}_{1} & =-\mathrm{T}^{\mathrm{v}}{ }_{2} \\
\nabla^{2} \mathrm{~T}^{\mathrm{v}}{ }_{2} & =-\mathrm{T}^{\mathrm{P}}{ }_{3 \mathrm{~A}}
\end{aligned}
$$

Denoting the number of points as $M$, we obtain the following integral equations from Eqs.(29) and (30)

$$
\begin{aligned}
& \mathrm{cT}^{\mathrm{V}}{ }_{1}(\mathrm{P})=-\sum_{\mathrm{i}=1}^{2}(-1)^{\mathrm{i}} \int_{\Gamma}\left\{\mathrm{T}^{*}{ }_{\mathrm{i}} \frac{\partial \mathrm{T}^{\mathrm{V}}{ }_{\mathrm{i}}(\mathrm{Q})}{\partial \mathrm{n}}-\frac{\partial \mathrm{T}^{*}{ }_{\mathrm{i}}}{\partial \mathrm{n}} \mathrm{T}^{\mathrm{V}}{ }_{\mathrm{i}}(\mathrm{Q})\right\} \mathrm{d} \Gamma-\sum_{\mathrm{m}=1}^{\mathrm{M}} \mathrm{T}^{*}{ }_{2 \mathrm{~A}} \mathrm{~T}^{\mathrm{P}}{ }_{3 \mathrm{~A}(\mathrm{~m})} \\
& \mathrm{cT}^{\mathrm{V}}{ }_{2}(\mathrm{P})=\int_{\Gamma}\left\{\mathrm{T}^{*}{ }_{1} \frac{\partial \mathrm{T}^{\mathrm{V}}{ }_{2}(\mathrm{Q})}{\partial \mathrm{n}}-\frac{\partial \mathrm{T}^{*}{ }_{1}}{\partial \mathrm{n}} \mathrm{T}^{\mathrm{V}}{ }_{2}(\mathrm{Q})\right\} \mathrm{d} \Gamma(\mathrm{Q})+\sum_{\mathrm{m}=1}^{\mathrm{M}} \mathrm{T}^{*}{ }_{1 \mathrm{~A}} \mathrm{~T}^{\mathrm{P}}{ }_{3 \mathrm{~A}(\mathrm{~m})}
\end{aligned}
$$

The boundary $\Gamma$ is discretized by the constant elements. Replacing $T^{v}{ }_{i}$ and $\partial \mathrm{T}^{\mathrm{V}}{ }_{i} / \partial \mathrm{n}$ by vectors $T_{i}$ and $V_{i}$, respectively, and expressing Eq.(31) as matrices, we obtain ${ }^{12}$

$$
H_{1} T_{1}=G_{1} V_{1}+H_{2} T_{2}-G_{2} V_{2}-G^{P}{ }_{2} T^{P}{ }_{3} \text {, }
$$

where $G_{1}, H_{1}, G_{2}, H_{2}$ and $G_{2}^{P}$ are the matrices with the following elements for a given boundary point 'e':

$$
\begin{aligned}
& G_{1 e j}=\int_{\Gamma_{j}} T_{1}^{*}(P, Q) d \Gamma_{j} \\
& H_{1 e j}=\frac{1}{2} \delta_{i j}+\int_{\Gamma_{j}} \frac{\partial T^{*}{ }_{1}(P, Q)}{\partial n} d \Gamma_{j} \\
& G_{2 e j}=\int_{\Gamma_{j}} T^{*}{ }_{2}(P, Q) d \Gamma_{j} \\
& H_{2 e j}=\int_{\Gamma_{j}} \frac{\partial T^{*}{ }_{2}(P, Q)}{\partial n} d \Gamma_{j} \\
& G^{P}{ }_{2 e k}=T^{*}{ }_{2 A k}\left(P, q^{P}\right) .
\end{aligned}
$$

$\Gamma_{j}$ is the discretized boundary. Notations $p$ and $q$ are used for internal points instead of $P$ and $Q$. When the case of $I=2$ is considered, the following equation is obtained from Eq.(32):

$$
H_{1} T_{2}=G_{1} V_{2}+G_{1}^{P} T_{3}^{P} \text {, }
$$


where $G^{P}{ }_{1}$ is the matrix with elements

$$
\mathrm{G}^{\mathrm{P}}{ }_{1 \mathrm{k}}=\mathrm{T}^{*}{ }_{1 \mathrm{~A}}\left(\mathrm{P}, \mathrm{Q}^{\mathrm{P}}\right)
$$

Moreover, using the internal points with value $T\left(p_{A}{ }_{A}\right)$ which is related to $\mathrm{T}_{3 \mathrm{~A}}^{\mathrm{P}}$, we obtain

$$
T\left(p^{P}\right)=-H_{3} T_{1}+G_{3} V_{1}+H_{4} T_{2}-G_{4} V_{2}-G^{P} T^{p}{ }_{3},
$$

where $G_{3}, H_{3}, G_{4}, H_{4}$ and $G_{3}^{P}$ are the matrices with elements

$$
\begin{aligned}
G_{3 e j} & =\int_{\Gamma_{j}} T^{*}{ }_{1}\left(p^{P}, Q\right) d \Gamma_{j} \\
H_{3 e j} & =\int_{\Gamma_{j}} \frac{\partial T^{*}{ }_{1}\left(p^{P}, Q\right)}{\partial n} d \Gamma_{j} \\
G_{4 e j} & =\int_{\Gamma_{j}} T^{*}{ }_{2}\left(p^{P}, Q\right) d \Gamma_{j} \\
H_{4 e j} & =\int_{\Gamma_{j}} \frac{\partial T^{*}{ }_{2}\left(p^{P}, Q\right)}{\partial n} d \Gamma_{j} \\
G^{P}{ }_{3 e k} & =T^{*}{ }_{2 A}\left(p^{P}, q^{P}\right) .
\end{aligned}
$$

Assuming $T_{2}=0$ and using Eqs.(33), (39) and (41), we obtain

$$
\left[\begin{array}{ccc}
G_{1} & -G_{2} & -G^{P}{ }_{2} \\
0 & G_{1} & G_{1}^{P_{1}} \\
G_{3} & -G_{4} & -G^{P_{3}}
\end{array}\right]\left(\begin{array}{c}
V_{1} \\
V_{2} \\
T^{P}{ }_{3}
\end{array}\right)=\left(\begin{array}{c}
H_{1} T_{1} \\
0 \\
H_{3} T_{1}+T\left(p^{P}\right)
\end{array}\right)
$$

Using the above equation, $V_{1}, V_{2}$ and $T^{\mathrm{P}}{ }_{3}$ can be obtained. The value at an arbitrary inner point can be obtained by Eq.(31).

Using the above method, a solid can be defined. Voxels can be used to show a solid object. Scanning inside the region, a small voxel is created if the value at the point is smaller than zero. This method can be easily applied to stereolithography. The other method is shown in Fig.5. First, coarse triangular patches are given, and normal vectors are given using Eq.(28) at the middle point of each side of the triangle. Searching the point of value zero, four new patches are made. Repeating this process, smooth surfaces can be obtained. Similarly, marchine cubes method can be used.

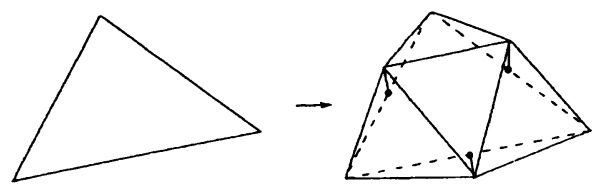

Figure.5 Generation of new surfaces 


\section{NUMERICAL EXAMPLES}

In this method, a fictitious big box, in which the solid is defined, is considered. The value of the box surface is assumed to be +1 . The surface of the box is divided into elements, as shown in Fig.6(a). In the simplest example, the free-form surface, defined by nine points on the surface and one internal point (Fig.6(b)), is obtained using several functions and parameters. As shown in Figs.7(a) (e), the surface becomes smooth by increasing the number $i$ of function $T_{i}^{*}$. If the same number $i$ is used, the surface defined by $T^{*}{ }_{i A}$ is smoother than that defined by $T_{i}^{*}$. The surface becomes smooth with increasing parameter $\mathrm{A}$. Using the constant elements and $\mathrm{M}$ internal points and dividing the boundary of the fictitious big box into $N$, the simultaneous linear algebraic equations with (IN+M) unknowns must be solved. If $\mathrm{T}^{*}{ }_{2 \mathrm{~A}}$ is used with a larger value of $\mathrm{A}$, the shape in Fig.7(b) is similar to the shape in Fig.7(c) and the calculation time is much shorter than that using $\mathrm{T}_{3}^{*}$.

To construct a shape with two projections, several smooth solids are created with the surface points as shown in Fig.8. The point with value +1 is given in the middle of the two projections in order to avoid connecting them. In this method, a solid is defined only by points, and Fig. 9 shows the voxel shape obtained from these points. It is a possibile to apply this method to stereolithography. If voxeles are used to construct the shape, the shape is unclear. The triangular patches are used to avoid this. First, the rough triangular patches are given, the fine triangular patches are calculated by using the method shown in Fig.5. Figures 10(a) and (b) show the shapes obtained using $\mathrm{T}_{\mathrm{f}}^{*}$ and $\mathrm{T}^{*}{ }_{2 \mathrm{~A}}$, respectively.

As a useful application of this method, a human face is obtained from surface points. Figure 11(a) shows the given surface points in the front view. Though points on the top of the head and the side of the face are not given as shown in Fig.11(a), a smooth surface is created through the calculation. Giving the patche by an operator requires far too much time, so 20 rough triangular patches are given using only 12 points as shown in Fig. 11(b). After repeating the calculation as shown in Fig.5 four times, a human face can be obtained from the given points as shown in Fig.10. Function $\mathrm{T}_{2 \mathrm{~A}}^{*}$ with $\mathrm{A}=0.05$ is used. It became clear that smooth solid modeling can be carried out using a limited amount of data.

Ray casting ${ }^{14}$ for modeling solids is effective for the present method. Surface points on the Venus de Milo are shown in Fig.13(a), and Fig.13(b) shows the side and front views of the Venus de Milo obtained by ray casting and Eq.(47). A solid can also be defined by lines instead of points. Figure 14(a) shows the given lines, and the obtained solid is shown in Fig.14(b). 


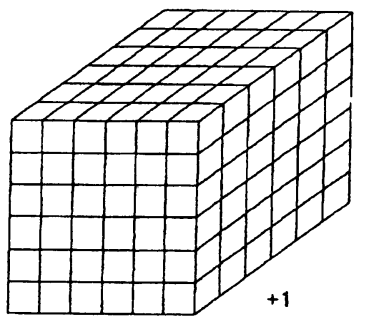

(a) Boundary

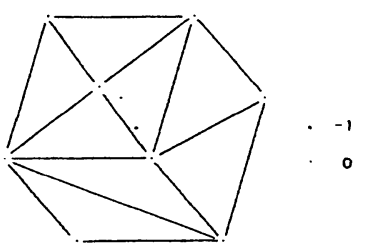

(b) Given points

Figure.6 Boundary and given points

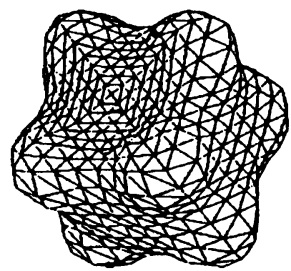

(a) $\mathrm{T}_{1 \mathrm{~A}}^{*}, \mathrm{~A}=1.5$

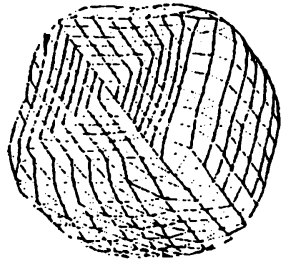

(b) $\mathrm{T}^{*}{ }_{1 \mathrm{~A}}, \mathrm{~A}=2$.

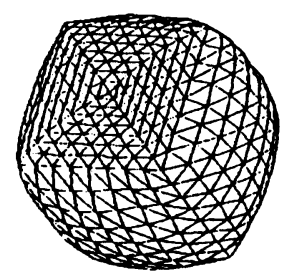

(c) $\mathrm{T}_{2 \mathrm{~A}}^{*}, \mathrm{~A}=0.1$

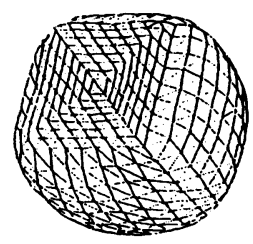

(d) $\mathrm{T}_{2 \mathrm{~A}}^{*}, \mathrm{~A}=1$.

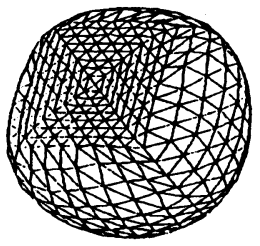

(e) $\mathrm{T}_{3}^{*}$

Figure. 7 Example of obtained shapes

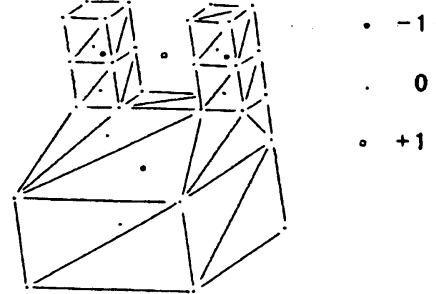

Figure. 8 Shape with two projections

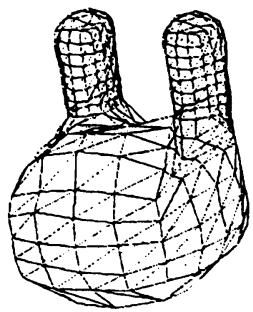

(a) $\mathrm{T}_{2 \mathrm{~A}}, \mathrm{~A}=0.3$

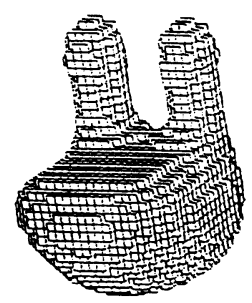

Figure. 9 Obtained voxel shape

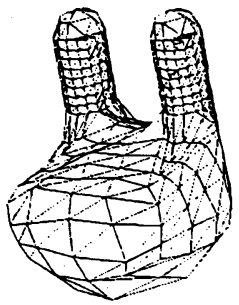

(b) $\mathrm{T}_{3}^{*}$

Figure. 10 Obtained shape 


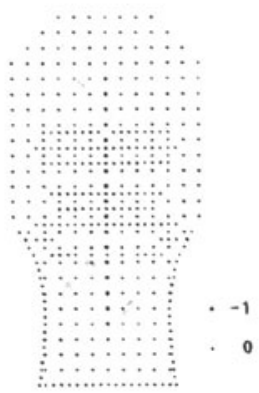

(a) Given surface points

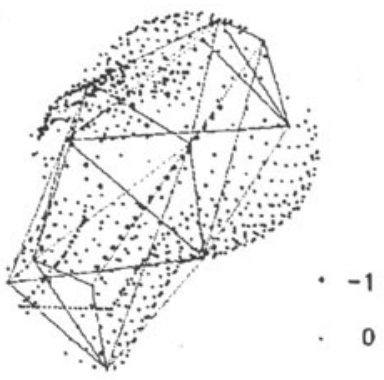

(b) Given patches

Figure. 11 Given surface points and patches

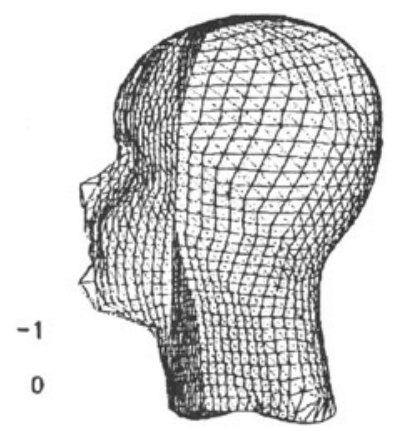

Figure. 12 Obtained shape

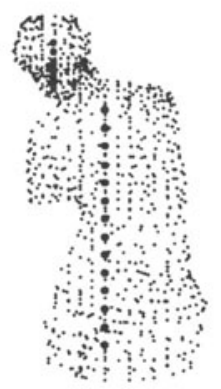

(a) Given points

Figure.13 The Venus de Milo

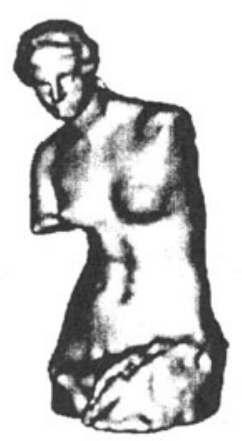

(b) Obtained solid

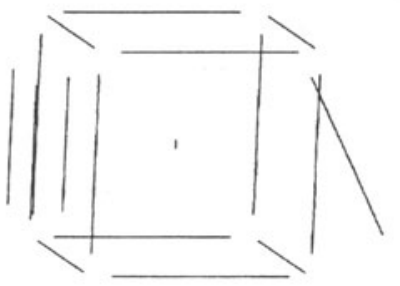

(a) Given lines

Figure.14 Solid using lines

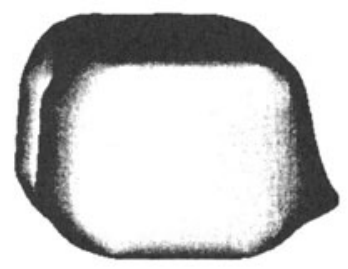

(b) Obtained solid

\section{CONCLUSION}

It has been shown that a smooth solid can be easily modeled using the boundary integral equations and three-dimensional polyharmonic functions. The smooth surface of a solid is defined only by points, therefore a smooth surface can be obtained by rough solid definition using points on the surface. A whole solid surface can be defined by only one surface patch. New functions, which express a state uniformly distributed with a polyharmonic function, are derived, and a new integral equation using these is shown. 
Using these new functions, the simultaneous algebraic equation becomes small.

\section{REFERENCES}

1 Foley J.D. and Dam A. Van, Fundamentals of Interactive Computer Graphics, Addison Wesly, New York.pp.191-550, 1984.

2 Farin G, Curves and Surfaces for Computer Aided Geometric Design, (1990), Academic Press.

3 Bloor M.I.G and Wilson, M.J, Using Partial Differential Equations to Generate Free-Form Surfaces, Computer-Aided Design, Vol.22, No.4,(1990), pp.202-212.

4 Welch W. and Witkin A., Variational Surface Modeling, Computer Graphics, Vol.26, No.2, (1992), pp.157-166.

5 Wyvill G., McPheeters C. and Wyvill B., Data Structure for Soft Objects, Visual Computer, (1998),Vol.2, pp.227-234.

6 Blinn J.F., A Generalization of Algebraic Surface Drawing, ACM Transactions on Graphics, Vol.1, No.3, (1982), pp.235-256.

7 Nira Dyn, Interpolation of Scattered Data by Radial Functions, in Topics in Multivariate Approximation, Eds. C.K. Chui, L. L. Schumaker and F. I. Utreras, pp.47-61, (1987), Academic Press, London.

8 Chales A. Micchelli, Interpolation of Scattered Data, Constructive Approximation, Vol.2, pp.12-22, 1986.

9 Ochiai Y. and Sekiya T., Generation of Free-Form Surface in CAD for Dies, Advances in Engineering Software, Vol.22, pp.113-118, 1995.

10 Ochiai Y., Generation Method of Distributed Data for FEM Analysis, JSME International Journal, Vol.39, No.1 (1996), pp.93-98.

11 Ochiai Y. and Sekiya T., Steady Heat Conduction Analysis by Improved Multiple-Reciprocity Boundary Element Method, Engineering Analysis with Boundary Elements, Vol.18, pp.111-117, (1996).

12 Brebbia C.A., Telles J.C.F. and Wrobel,L.C., Boundary Element Techniques - Theory and Applications in Engineering, pp.47-107, Berlin, Springer-Verlag, 1984.

13 Ochiai Y. and Yasutomi Z., Improved Method Generating a Free-Form Surface Using Integral Equations, Computer Aided Geometric Design, Vol.17, pp.233-245, (2000).

14 Roth S.D., Ray Casting for Modeling Solids, Computer Graphics and Image Processing, Vol.18, (1982), pp.109-144. 